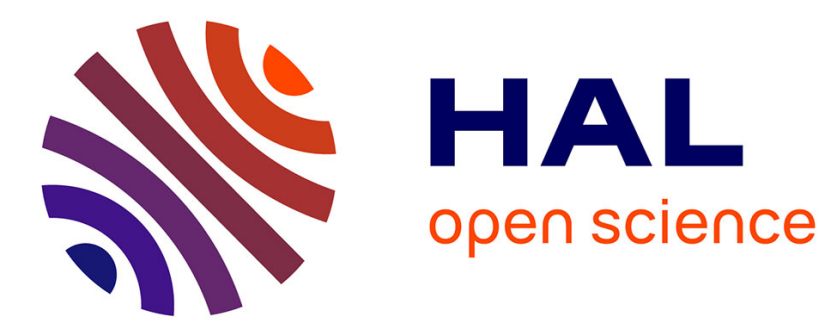

\title{
Comparative environmental life cycle assessment of materials in wooden boat ecodesign
}

Regis Pommier, Guilhem Grimaud, Marion Princaud, Nicolas Perry, Guido

Sonnemann

\section{- To cite this version:}

Regis Pommier, Guilhem Grimaud, Marion Princaud, Nicolas Perry, Guido Sonnemann. Comparative environmental life cycle assessment of materials in wooden boat ecodesign. International Journal of Life Cycle Assessment, 2016, 21 (2), pp.265-275. 10.1007/s11367-015-1009-1 . hal-01302624

\section{HAL Id: hal-01302624 \\ https://hal.science/hal-01302624}

Submitted on 14 Apr 2016

HAL is a multi-disciplinary open access archive for the deposit and dissemination of scientific research documents, whether they are published or not. The documents may come from teaching and research institutions in France or abroad, or from public or private research centers.
L'archive ouverte pluridisciplinaire HAL, est destinée au dépôt et à la diffusion de documents scientifiques de niveau recherche, publiés ou non, émanant des établissements d'enseignement et de recherche français ou étrangers, des laboratoires publics ou privés. 


\title{
Comparative environmental life cycle assessment of materials in wooden boat ecodesign
}

\author{
Régis Pommier $^{1}$ (1) • Guilhem Grimaud ${ }^{1} \cdot$ Marion Prinçaud $^{1} \cdot$ Nicolas Perry $^{1,2}$. \\ Guido Sonnemann ${ }^{3}$
}

\begin{abstract}
Purpose Wooden boatyard building was replaced in the 1970s in favor of materials which are considered cheaper and simpler to work with (such as composite or aluminum). With today's new environmental standards, the choices of materials must also be compatible with the aims of ecodesign. We promote wood-based boats and the replacement of exotic woods with local varieties (from France). An environmental impact assessment is needed to clarify the relative position of each solution.

Methods In order to validate the choices, we used a life cycle assessment (LCA) "from cradle to grave" of the hull. This LCA is based on the comparison of the following different materials used: aluminum, composite, exotic wood, and maritime pine. This study is based on the construction of an 18-mlong passenger transport boat. These evaluations were carried out with respect to ISO 14040 standards, beginning with an existing database and measurements taken on the building and production sites.

Results and discussion Our results demonstrate the benefits of using a wood-based hull compared with other materials. Moreover, the results show that the maritime pine used in
\end{abstract}

Responsible editor: Holger Wallbaum

Régis Pommier

regis.pommier@u-bordeaux.fr

1 I2M, UMR 5295, CNRS - University of Bordeaux, 351 cours de la Libération, 33405 Talence, France

2 Arts et Metiers ParisTech Bordeaux, I2M, UMR 5295, Univ. Bordeaux, Esplanade des Arts et Métiers, 33405 Talence Cedex, France

3 ISM, UMR 5255, CNRS - University of Bordeaux, 351 cours de la Libération, 33405 Talence, France replacement of imported exotic woods is more favorable from both economic and environmental points of view. This LCA allowed us to characterize precisely the stages in the life cycle of a passenger boat and to propose a hierarchy of the different materials under comparison for the purposes of boat building. Conclusions The recommendations and lines of progress highlighted by this study will allow us to enhance the efficiency of upcoming constructions and to promote the ecodesign conception in the boatyard.

Keywords Boat building $\cdot$ Ecodesign $\cdot$ Life cycle assessment $\cdot$ Maritime pine $\cdot$ Wood

\section{Introduction}

\subsection{Context of the study}

In its choice of materials, boat building must find technical solutions which will make the boats robust and long lasting at the optimum weight. Boatyards have always been concerned with developing and using new materials in response to their customers' requests (Jacob 2012). The generalization of composite materials in boat building over the past 50 years is a response to the problem of weight gain while still maintaining a high level of rigidity and resistance (Marsh 2006). Today, nearly $95 \%$ of pleasure craft is made of composites (D'Aboville 2009).

The IPCC estimates that maritime transport contributes between 3 and $5 \%$ to the global emissions of greenhouse gases (IPCC 2014). The rising awareness of climate change on a global scale as well as the impact on the sea led France (Levrel et al. 2014) and Europe to set up a policy for the protection of marine areas. Up to the present, the protection of marine environments has been concentrated on a more 
reasonable use of marine resources (Bertram and Rehdanz 2013). Marine conservation areas are a local response to global problems (Mcleod 2013), and this poses the problem of finding effective and long-lasting solutions. This is why it seems necessary to integrate the idea of sustainable development into boat building. Over the past few years, the International Marine Organization (IMO) has proposed the reduction of environmental impacts from the emissions from passenger ships (International Marine Organization 2005). However, all boats do not enter into this category (such as pleasure crafts, small boats, or those used on inland waters) and their environmental impacts remain significant on a world level (van der Zee et al. 2012). This idea of respect for the environment is crucial when the boat is used in a conservation area (Ministry of Ecology 2012).

The first scientific studies examined the number of elements which might have an environmental impact on boat design (Stoyell et al. 1999). In 2008, Cabezas-Basurko et al. (2008) proposed a methodology for a sustainability analysis of ships. Ridley and Hutchinson (2012) set up a model which could integrate environmental considerations into boat design. At that time, life cycle analyses were being developed considerably $\left(\mathrm{CO}_{2}, \mathrm{NO}_{X}, \mathrm{SO}_{X}\right.$, and others-volatile organic compounds, VOC) with, for example, the use of better quality fuels as well as the use of technical solutions to counter these emissions. Attention has also been paid to the disposal of these (degassing, holding tank systems) with ever stricter regulations aiming at the reduction of waste and pollution at sea. Therefore, few boatyards have focused on the impact of the materials used and on the solutions that aim to reduce the environmental impact of boat building. A French National Research Agency (ANR) program took place between 2008 and 2011 and brought together DCNS (French military ship builder), Ifremer (maritime expert), Sita Suez (waste management expert), and Arts et Métiers ParisTech (ecodesign expertise). The program aimed at assessing environmental impacts during the entire life cycle and improving environmental performances Princaud et al. $(2010 ; 2011)$. The research team developed an ecodesign tool to assess the impacts of ships during their manufacture, use, and end-of-life stages and especially on the marine environment.

Small units, under $8 \mathrm{~m}$, account for $80 \%$ of the boatbuilding market in France (Ministry of Ecology 2013). In fact, the French industry, which ranks fifth in the pleasure boatbuilding industry, is mainly made up of very small businesses with fewer than 20 employees in $75 \%$ of these firms. In contrast, the four or five biggest pleasure boat yards together represent about $60 \%$ of the number of employees. Exports represent $65 \%$ of the turnover for the major shipyards, so the market share for each boat builder remains tiny. The SME size of these enterprises quickly limits the human and financial means when it comes to responding to the criteria for sustainable development. Nevertheless, a large number of builders have expressed an interest in environmental issues.
Without any constraining regulations, boatyards do not carry out research into choice of materials on their own and they must outsource their research for ecodesign. For example, boat propulsion is produced by multinationals, and every year, these manufacturers are able to invest in research in order to comply with the ever stricter regulations on polluting emissions so they can build more efficient motors.

\subsection{Presentation of the ecodesign principle}

Faced with the challenges thrown up by the reduction of the impact of boats in the Arcachon Bay conservation area (a semi-enclosed lagoon), a boatyard has been made aware of the principle of ecodesign to reduce the impact of its boats. The boatyard has focussed its research along two lines: motorization and the usage of wood. These two themes have not only allowed the reduction of the boat's impact while it is being used but also the impact of its construction. Studies were made by a network foundation (EcoNav network 2012) in the field of boat building. It had shown that $90 \%$ of the impact of a motor boat's life cycle occurs during its use phase. So, reducing the weight of a boat with the help of an optimized design will mean that fuel consumption will be reduced and so will the overall impact of the boat.

Although the innovations in the field of motorization may come from other means of transport (land and air), the materials used are still very specific to boats. This is why the research focused on materials used in shipbuilding. The boatyard has remained faithful to the tradition of building wooden pinasses (a typical working boat before being transformed into a recreation boat in Arcachon Bay), and so it continues building wooden boats. Nevertheless, it turned away from using local wood resources and has been using more and more tropical wood (from Africa and South America).

Wood is a natural material from a renewable resource, and for a long time, it was the only material used in boat building. Like most natural materials, wood exhibits anisotropic properties and a large variability. The safety coefficients applied to wooden constructions (Bureau Veritas 2012) have increased the limits on design and reduced the competitive interest of this material. Also, wood is a material which is difficult to bend when shipbuilding design needs shapes. Today, wood is used in only $2 \%$ of pleasure boats (D'Aboville 2009). On the other hand, composite materials and aluminum offer a greater flexibility in their use and they guarantee homogeneity in mechanical performances. However, wood is highly durable and can last over 100 years with proper maintenance (EcoNav network 2011) whereas the average lifespan of boats in France is 30 years (Foundation APER 2012a). The optimization of construction in wood would allow weight decrease and make a very good compromise between mass and mechanical resistance with the use of a new type of plywood (Pommier and Elbez 2006; Lavalette et al. 2012). 
Our study was concentrated on the choice of materials to determine the interest in local resources and to develop technological solutions in order to guarantee the boat's competitive interest. When aluminum and composite material dominate the market, wood could help reduce the boat's impact during construction. The choice of maritime pine as a basis for work is explained by the proximity and the abundance of timber to the boatyard. Maritime pine also has a long history as the main material for the construction of pinasses in Arcachon Bay. This wood species answers well to the demands imposed on boat building even though, until recently, it has been replaced by exotic wood.

Until now, any life cycle assessments (LCAs) have been carried out on the use of boats under particular conditions focusing on the emission of pollutants. Our work is to highlight the interest of the environmental evaluation of a range of boats from "cradle to grave." By doing a global comparative LCA, we wanted to find out the benefits of wooden material in a concrete application (boat hulls). We validate the pertinence of substituting maritime pine for exotic woods with a view to furthering maritime ecodesign.

\section{Methods}

\subsection{The story of the boat under study}

The first boat was launched in the spring of 2012 and was a traditional 15-m pinasse built of exotic African wood material for private use. The aim was to study the feasibility of a zeroemission propulsion in order to minimize the environmental impact when it was in use. The second craft was an ecodesigned boat which can carry 45 people and six bikes. Its hull, in reinforced aluminum, is able to withstand specific conditions such as a strong current or tricky weather conditions. This commercial passenger transport boat, named Greenboat step 1, went into service on March 2013 as river transport on the Garonne in Bordeaux (France). It has hybrid propulsion (diesel/electric) and much advanced technology to limit its emission of greenhouse gases. Still in this range, the latest boat is a passenger transport boat built in response to a call for projects from COBAS, the South Arcachon Bay association (COBAS 2010). This wooden boat meets two specifications: respect for traditions (made with local wood) and for the environment (production and use). It is an 18-m wooden passenger transport boat with hybrid propulsion. The hull design is optimized in order to increase stability as well as to reduce consumption and damage. This boat (Greenboat step 2) has been the subject of a life cycle assessment (LCA). The boatyard built its research around two issues: propulsion and the use of wood. In the case of the first issue, the next stage in the yard is to be able to propose hydrogen propulsion and greater energy efficiency.

\subsection{Framework for the environmental evaluation}

\subsubsection{Methodology}

We carried out a LCA of Greenboat step 02 (Grimaud et al. 2013). The boat profile is given on Fig. 1. The study was done on the model of a comparative environmental LCA of several material solutions for the hull while respecting the ISO 14040 standard (ISO 2006). The LCA seems to be the most robust multicriteria tool to measure the environmental gains and to help us advance in our ecodesign project. This LCA allowed us to compare maritime pine as opposed to three other materials used in boat building: aluminum, composite (glass fiber/ epoxy), and African woods (CP Okoume and structure in Sapelee).

\subsubsection{Functional unit}

We decide to focus on the building material so we reduced the research campaigns on the hull. The principle of a hull is not to be autonomous. It is a sub-assembly which requires a propulsion system, for example, in order to become a functional whole. Nevertheless, the hull of the ship is the foundation on which other elements are added. We will turn to the hull and basic deck without the additions necessary for the correct functioning of the boat.

The functional unit (FU) is the transport of 60 passengers and 20 bikes (a load capacity of $5.5 \mathrm{t}$ ) through Arcachon Bay, in continuous service and in all weather conditions, and over a 30-year period.

\subsubsection{Boundaries of the system}

The aim of our work was to be as exhaustive as possible in order to include all of the life cycle, so as to take into account the real impacts as close as possible to reality. In Fig. 2, we show schematically the life cycle of the boat under study and the limits of the field of study. We are not including the storage period seeing that the boat is due to give continuous use. The boat will only leave the water for repairs and maintenance.

Particular attention has been paid to the displacement of pollution. In fact, the advantages gained in the construction can be easily wiped out by the needs for maintenance products all throughout its working life or by excessive use linked to the weight of the boat.

\subsection{Presentation of the scenarios studied}

By doing a global comparative "cradle to grave" LCA, we wanted to find out the benefits of different raw materials in a concrete application. We choose four naval construction 


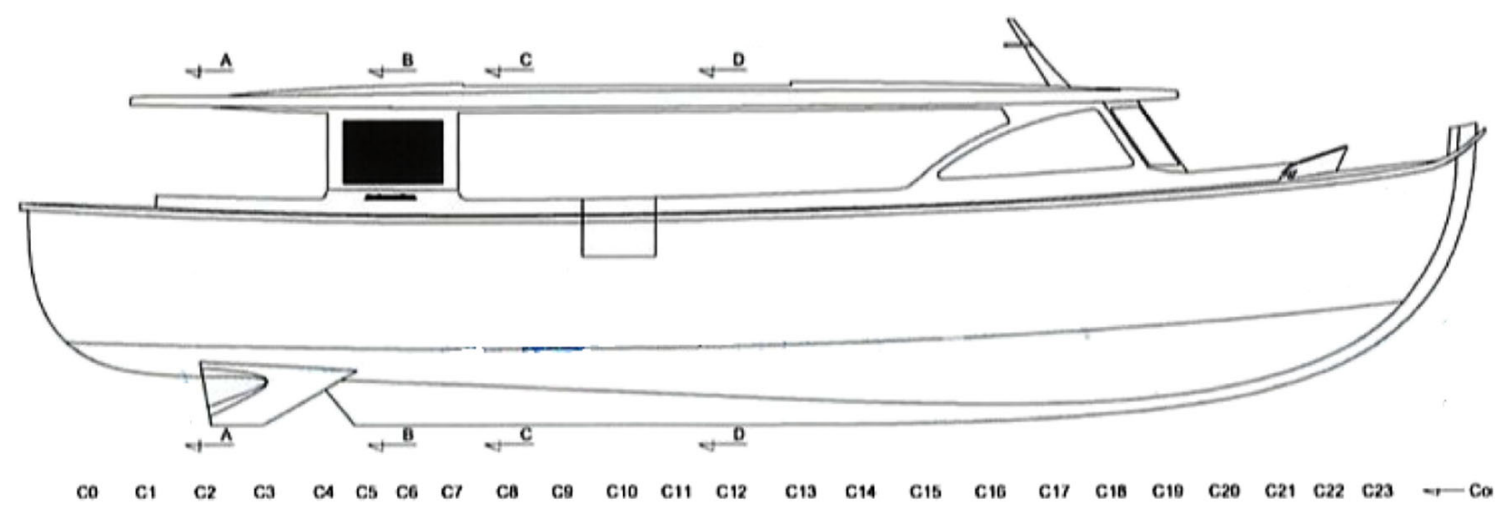

Fig. 1 Profile view of the Greenboat step 2

scenarios to study boat hulls of which used a different construction material:

- Scenario 1: aluminum hull

- Scenario 2: hull made from a composite stratified sandwich of fiber glass and polyester

- Scenario 3: hull made of African wood (Sapele and Okoumé)

- Scenario 4: hull made of local wood (maritime pine and oak)

\subsubsection{Presentation of scenario 1}

Dubourdieu boatyard has already built some boats in aluminum, so we used data construction from those boats, especially from Greenboat step 1, which was built a few years before.
We completed the inventory with data from EcoNav which already makes comparative LCA for aluminum boats (EcoNav Network 2012).

All the materials used from the modeling in SimaPro were already available in the Ecoinvent database so we did not create a new data sheet for this scenario. We set up the aluminum recycled rate at $40 \%$ (Roussel 2012), and the aluminum production site is at St Jean de Maurienne (France), $875 \mathrm{~km}$ away from the boatyard.

At the end of the life of the hull, we assume that $95 \%$ of the aluminum parts will be recycled. We took into account the transportation to a nearby recycling center and the dismantling phase $(100 \mathrm{~km})$. We use French waste processes for the non-aluminum parts and for $5 \%$ of the aluminum, which is landfilled (40\%) or incinerated (60\%) (Champion et al. 2013).
Fig. 2 Life cycle boat hull phases/boundary system

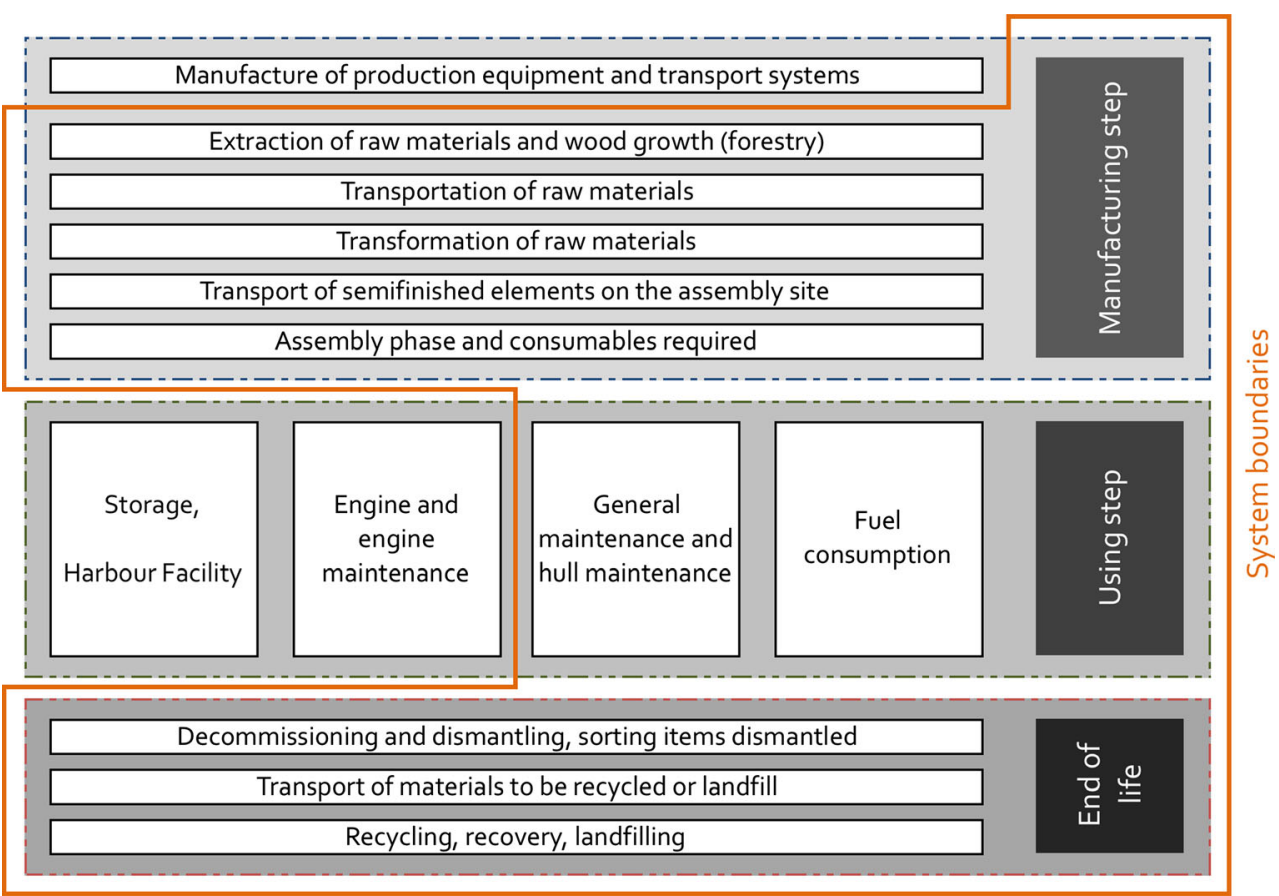




\subsubsection{Presentation of scenario 2}

The Dubourdieu boatyard has a certain amount of experience in building with wood (local or African) but does not have comparable skills with composite materials. We therefore called upon other sources of data in order to model the Greenboat step 02 with a composite hull for scenario 2 . These data mainly come from other sites where EcoNav carried out environmental evaluations and also from the design office.

As in scenario 1, we use data from the Ecoinvent library to model the building steps and the materials used. Our composite is made with polyester, epoxy resin, and glass fiber. All those materials come from French factories $650 \mathrm{~km}$ away from the boatyard.

For the end of life, we assume that metallic parts are recycled, and $80 \%$ of the composite hull is used as a combustible in the cement industry. As in scenario 1, we use French waste processes for the other parts, which are landfilled (40\%) or incinerated $(60 \%)$.

\subsubsection{Presentation of scenario 3}

Wooden boat construction is the specialty of Dubourdieu boatyard, so we used previous boats to build up the data for this scenario. Due to the lack of data modeling wood species in the Ecoinvent database, we used data from studies by the French wood building federation (FCBA). These data allowed the FCBA to publish EPDs of different products.

The wood used for this scenario mainly comes from Africa (Gabon and Cameroun), so the transport is done by boat $(8500 \mathrm{~km})$ to Le Havre harbor and then by truck to the shipyard $(950 \mathrm{~km})$.

For the end of life, we assumed that metallic parts are recycled. Sixty percent of the wood from the hull is used as combustible energy and $25 \%$ as particle board. As in scenario 1, we use French waste processes for the other parts (15\%), which are landfilled $(40 \%)$ or incinerated $(60 \%)$.

\subsubsection{Presentation of scenario 4}

For the wood used in scenario 4 , we get the data from the Aquitaine wooden federation (FIBA) which has already done life cycle assessments for pine wood. The wood comes from the south west of France by truck $(65 \mathrm{~km})$. The end-of-life scenario is assumed to be the same as in scenario 3 .

\subsubsection{Main information about scenarios}

For the four scenarios, the study intends to compare state of the art construction methods in Europe. Thus, we have used the most representative technologies for each of the scenarios. In Table 1, we list all the flows for each scenario.

\subsubsection{Sources of data and requirements}

Although we worked with different data sources, we are committed to sticking as closely to the quality requirements of the Ecoinvent database as possible. Thus, we are able to consider that the comparison is done at constant structure. The boundaries of each subsystem are comparable (Table 2).

\subsection{Hypotheses formulated}

\subsubsection{Length of life of the system}

The length of life of a boat varies according to the use made of it, how it is maintained, and the material from which it is built. For each solution, we will presume careful maintenance which will maximize the life of the boat. Some examples of the average life of a pleasure boat (Pensec and Pinon 2007), for systems close to our own FU, are the following:

- Hull made from a composite stratified sandwich: from 30 to 50 years

- Wooden hull: a hundred years or more

- Aluminum hull: 50 years or more

In fact, the length of life of each of these four solutions is different and we have chosen to consider the limiting life span of the composite material hull. Our study just looks at the life span of the hull in the bay, but it would be logical to consider that after 30 years, the hull could undergo a refit for further use. This hypothesis will be integrated into the solutions for wood and aluminum.

\subsubsection{Elements taken into account in our study}

In our study, we have considered the following elements for each solution:

- The first step taken into account is the extraction of the raw materials needed for the hull.

- The transformation of materials into pieces/sub-assemblies/assemblies.

- The assembly of pieces/sub-assemblies/assemblies until the final product is obtained.

- The maintenance and renovation during the working life.

- The consumption of the energy necessary for the boat's propulsion.

- The end of life of elements according to the waste disposal process.

- The transport of these to disposal plants. 
Table 1 Summary of the reference flows and other data used for the model

\begin{tabular}{|c|c|c|c|c|c|}
\hline & Reference flows & $\begin{array}{l}\text { Sol. } 1 \\
\text { Aluminum }\end{array}$ & $\begin{array}{l}\text { Sol. } 2 \\
\text { Composites }\end{array}$ & $\begin{array}{l}\text { Sol. } 3 \\
\text { Exotic wood }\end{array}$ & $\begin{array}{l}\text { Sol. } 4 \\
\text { Maritime pine }\end{array}$ \\
\hline \multirow[t]{4}{*}{ Overview } & Shell weight (kg) & 3645 & 3915 & 3585 & 4215 \\
\hline & Structure weight (kg) & 7210 & 6450 & 4815 & 3785 \\
\hline & Hull weight (kg) & 10,855 & 10,365 & 8400 & 8000 \\
\hline & Displacement & 23,355 & 22,865 & 20,900 & 20,500 \\
\hline \multirow[t]{5}{*}{ Maintenance } & Antifouling paint & Without metallic ions & With copper & With copper & \\
\hline & Applications & Each year & Every 5 years & Every 5 years & \\
\hline & Paint and varnish & 2 times/life & 2 times/life & 1 paint and 15 varnishes & \\
\hline & Gelcoat & None & A new one & None & \\
\hline & Zinc anode & $1.5 \mathrm{~kg}$ each year & $1.5 \mathrm{~kg}$ for 10 years & $1.5 \mathrm{~kg}$ for 10 years & \\
\hline \multirow[t]{2}{*}{ End of life } & Lifetime & 60 years & 30 years & 100 years & \\
\hline & Treatment system & Recycling & Solid recovered fuel & Wood energy and particle board & \\
\hline Data & Data sources & Greenboat step 01 & EcoNav other shipyards & Past construction from Dubourdieu & Greenboat step 02 \\
\hline
\end{tabular}

Just like for the mineral elements, the growth and the exploitation of the wood is taken into account - the forestry phase.

\subsubsection{Elements excluded from our study}

There are nevertheless certain elements which are difficult to quantify or are supposedly insignificant, according to the standard ISO 14 040. We will not consider the following:

- Lighting, heating, and the cleaning of workshops.

- All of the small material (gloves, masks, etc.).
- The administrative department of the yard.

- Transport of employees and customers to the yard.

- The manufacture of production tools (industrial site, machine tools, etc.).

- The construction of transport systems (handling equipment, boat, trucks, etc.).

- The storage phase and port structures.

- The motorization and the maintenance of motors are not studied in this LCA. A complementary LCA of the hybrid system must be done.

- Fittings on the boat for the transport of passengers.

Table 2 Main data input of the life cycle phases

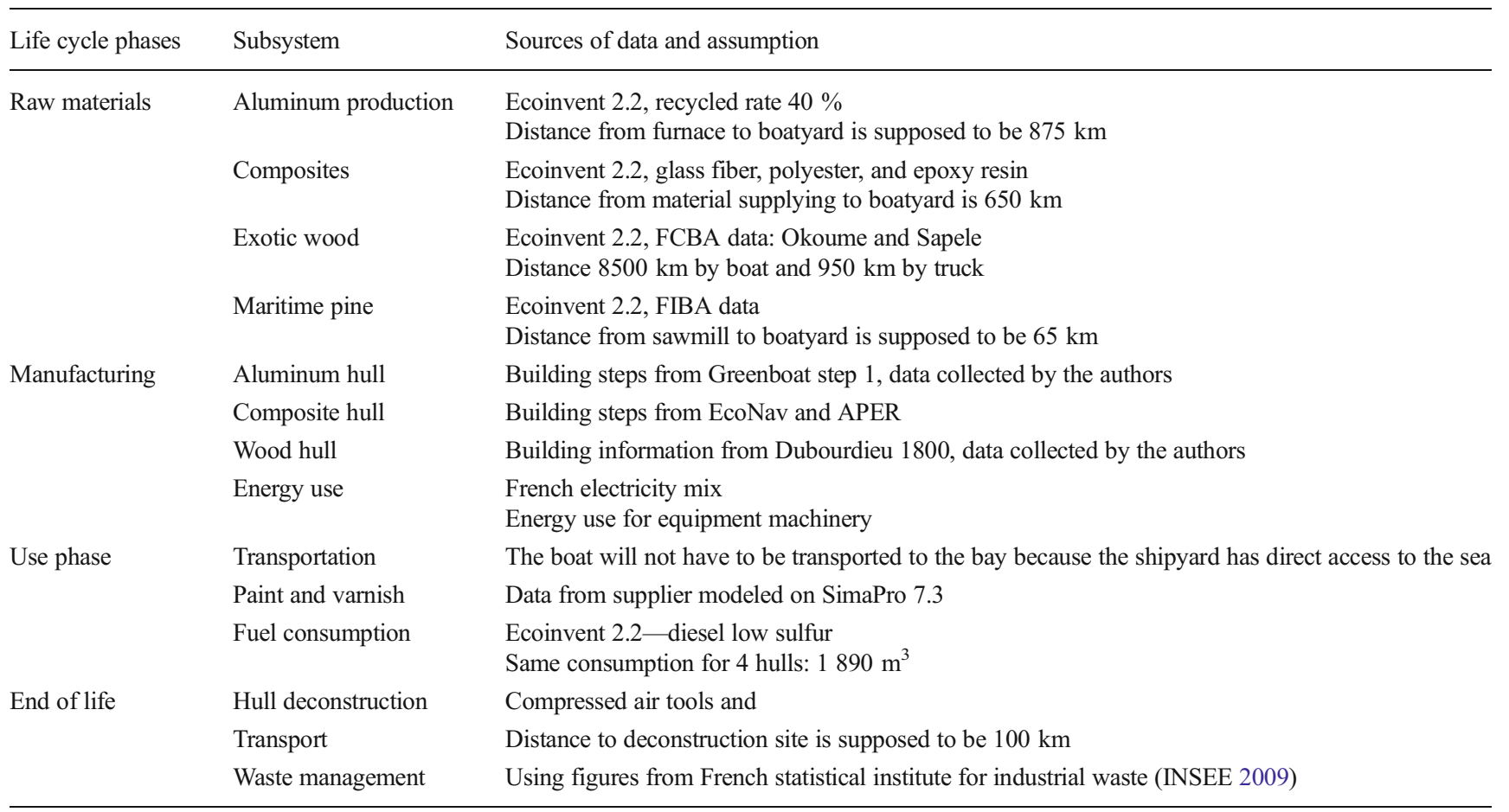




\subsubsection{Assumptions retained in the study}

We announced the following propositions which are valid for all the solutions examined:

- All transport is carried out in the most direct manner possible.

- The means of transport used are based on reality.

- The site for handling raw material is selected for being as close as possible to the assembly site.

- The assembly site is the Dubourdieu yard, ${ }^{1}$ for all the solutions.

- Even though the boat's fittings are not included in our study, their weight must be taken as identical in all four solutions.

- The phases for repair and maintenance are carried out as is customary.

- Dismantling and breaking apart take place on an approved site (Foudation APER 2012b).

- The storage element that appears in the active phase is considered as null seeing as the boat is used continuously during its life span.

\subsection{Choice of the characterization model}

\subsubsection{Method for the calculations and the software}

The aggregation of data and LCA impact calculation came from Simapro 7.3 software. The results given hereafter were obtained using the following method of calculation: ReCiPe Europe MidPoint Hierarchist (H) V1.06 (Ministry of Housing Spacial Planning and the Environment 2009). The results presented were calculated using the European method and not the worldwide one.

ReCiPe was chosen because it incorporates intermediate categories of impact and damage. In addition, ReCiPe includes update improvements of existing methods (Goedkoop et al. 2009). It was also the most robust method at the time of the beginning of the study in 2013 .

\subsubsection{Choice of indicators}

The ReCiPe Midpoint method gives the results for 18 environmental impact indicators, but not all of these are significant or useful for our purpose. In order to facilitate our interpretations and to make use of the representative data, we have selected only eight indicators which are the most representative of global trends. The choice of indicators was made by

\footnotetext{
${ }^{1}$ Chantier Naval Dubourdieu 1800, Port de Larros, 33470 GujanMestras, France
}

studying the results obtained in the form of normalized graphs and according to three lines of research (Tukker 2002).

Firstly, we chose two emblematic indicators: climate change and human toxicity which seem able to easily summarize the global impact of the solutions. These two indicators are easy to give the general trend for the solutions under study. Secondly, in order to promote the solutions which are the most viable over time and which are the most efficient, we included the indicators for the depletion of metal and fossil resources. These are powerful and emblematic indicators for the comparative LCAs of manufactured products (Curran 2012).

Finally, we placed ourselves in the context of the study, that is to say the marine use of manufactured plywood. We chose to highlight those indicators linked to the marine world: marine eutrophication and marine ecotoxicity, even though there are more serious uncertainties here (European Commission 2010).

In order to validate the ecodesign result preferring the use of local harvested wood, we also integrated into our two indicators a link to the cultivation of wood: the transformation of natural land and terrestrial acidification.

After starting with the reading of normalized graphs, we were able to validate or modify the choice of indicators and thus conserve a pertinent and readable set of indicators within the framework of the environmental evaluation. We can cite two indicators which, despite their pertinence, only appear in the case of Ecoinvent database (DB) solutions on the normalized histograms: toxicity of the earth and depletion of water resources. We have chosen to leave them aside in order not to discriminate against generic solutions.

\section{Results of the life cycle impact assessment}

\subsection{Comparison by life phases}

\subsubsection{Construction phase}

Figure 3 shows that the aluminum hull has a very strong impact compared to the three other solutions in the phase of construction. One exception to this statement concerns the depletion of metal resources. The composite hull does not use more metal resources but uses more critical metals in alloys. Composite structure means a higher demand of stainless steel for the hull-deck joint, causing a higher stress in this indicator. Similar observation for the two wooden hulls compared to aluminum, widely available from recycling, can be made. For scenario 1, the network shows us that the impact is mainly due to the aluminum material itself and production stages. The transformation of bauxite alumina into aluminum contributes mainly to the final impact. Thanks to the recycled aluminum used in hull building, these stages are reduced. 
Fig. 3 Comparison of the hull assembly phase for the four scenarios-Method ReCiPe Midpoint (H) v1.06

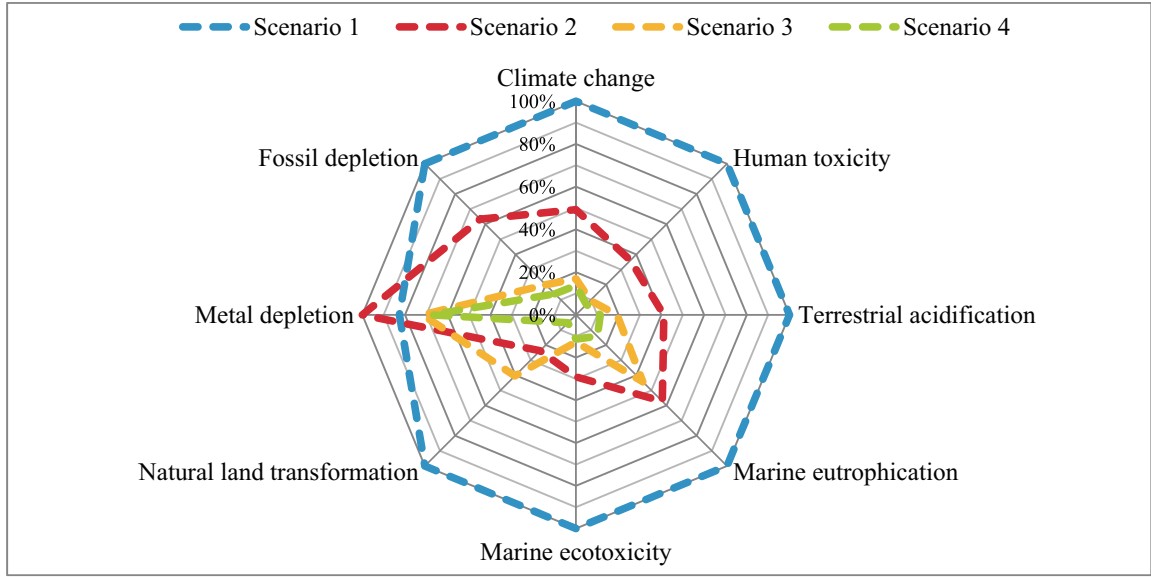

\begin{tabular}{llrrrr}
\hline Impact category & Unit & \multicolumn{1}{c}{ Scenario 1 } & \multicolumn{1}{c}{ Scenario 2 } & \multicolumn{1}{c}{ Scenario 3 } & \multicolumn{1}{c}{ Scenario 4 } \\
\hline Climate change & $\mathrm{kg} \mathrm{CO}$ eq & $1.40 \mathrm{E}+05(100 \%)$ & $6.89 \mathrm{E}+04(49 \%)$ & $2.36 \mathrm{E}+04(17 \%)$ & $1.91 \mathrm{E}+04(14 \%)$ \\
Human toxicity & $\mathrm{kg} \mathrm{1.4-DB} \mathrm{eq}$ & $6.30 \mathrm{E}+04(100 \%)$ & $2.27 \mathrm{E}+04(36 \%)$ & $5.99 \mathrm{E}+03(10 \%)$ & $4.34 \mathrm{E}+03(7 \%)$ \\
Terrestrial acidification & $\mathrm{kg} \mathrm{SO}^{2}$ eq & $5.61 \mathrm{E}+02(100 \%)$ & $2.31 \mathrm{E}+02(41 \%)$ & $1.08 \mathrm{E}+02(19 \%)$ & $6.41 \mathrm{E}+01(11 \%)$ \\
Marine eutrophication & $\mathrm{kg} \mathrm{N} \mathrm{eq}$ & $2.56 \mathrm{E}+01(100 \%)$ & $1.47 \mathrm{E}+01(57 \%)$ & $1.13 \mathrm{E}+01(44 \%)$ & $3.63 \mathrm{E}+0(14 \%)$ \\
Marine ecotoxicity & $\mathrm{kg} \mathrm{l.4-DB} \mathrm{eq}$ & $1.58 \mathrm{E}+03(100 \%)$ & $4.58 \mathrm{E}+02(29 \%)$ & $2.02 \mathrm{E}+02(13 \%)$ & $1.79 \mathrm{E}+02(11 \%)$ \\
Natural land transformation $\%)$ & $\mathrm{m}^{2}$ & $2.68 \mathrm{E}+01(100 \%)$ & $6.37 \mathrm{E}+0(24 \%)$ & $1.08 \mathrm{E}+01(40 \%)$ & $1.41 \mathrm{E}+0(5 \%)$ \\
Metal depletion & $\mathrm{kg} \mathrm{Fe} \mathrm{eq}$ & $7.00 \mathrm{E}+03(83 \%)$ & $8.47 \mathrm{E}+03(100 \%)$ & $6.08 \mathrm{E}+03(72 \%)$ & $5.72 \mathrm{E}+03(68 \%)$ \\
Fossil depletion & $\mathrm{kg}$ oil eq & $3.75 \mathrm{E}+04(100 \%)$ & $2.37 \mathrm{E}+04(63 \%)$ & $7.47 \mathrm{E}+03(20 \%)$ & $5.22 \mathrm{E}+03(14 \%)$ \\
\hline
\end{tabular}

On the other hand, for most indicators, scenario 2 correspond to the solution which is the second most damaging environmentally in the construction phase, except for the indicator on the transformation of natural land where scenario 3 is in second place. Even if its impact is between 30 and $85 \%$ less severe on our set of indicators than for the aluminum solution, it does not remain an environmentally sustainable solution. The impacts mainly come from the resin polyester which represents more or less $60 \%$ of the final hull impact. Electricity use is also a main contributor for $20 \%$.

For scenario 3, polyester resin used for coating is a huge contributor in the overall impact of the hull. The method for logging in Africa leads to a very strong impact. In natural land transformation indicator, wood is responsible of $73.4 \%$ of the impact on the indicator. Transport to Europe represents $8 \%$ of the final impact for the hull.

For scenario 4, the impact of transport is negligible and the forest management leads to a very low impact on natural land transformation.

\subsubsection{Use phase}

Figure 4 represents the repartition of the fossil depletion during the complete life cycle. Scenario 1 is only represented because it is considered as the most influent during construction phase. This representation allows us to focus that the depletion of fossil resources is almost exclusively due to the fuel consumed during the boat's working life.
As we could easily predict, the result shows that fuel is the first element to impact on the life span of hulls. Energy consumption in the construction phase is largely surpassed by the consumption during the working life phase. It represents over $99 \%$ of the impact for scenario 1 and over $98 \%$ for the other scenarios on the whole of the life cycle ( $98.8 \%$ for scenario 2 , $99.6 \%$ for scenario 3 , and $99.8 \%$ for scenario 4 ). Our study is aiming to highlight the comparison of the materials themselves. For this reasons, we do not make any difference in fuel consumption between each scenario, even if the hulls have different weight. For example, the wooden hull of scenario 4 is $13 \%$ lighter than scenario 1 so we could have imagined lower fuel consumption.

\subsubsection{End-of-life phase}

We noted, during the comparison of the four scenarios, the benefits of recycling at the end of the life cycle for our four solutions and especially for the indicator of metal resource depletion. In fact, for each of the four end-of-life scenarios, we have envisaged a high level of metal recycling.

For the aluminum scenario, the end-of-life phase allows the compensation of between 40 and $60 \%$ of the impact during the construction of the hull. This advantage is essential in the case of sustainable construction. The energy and the materials saved by this recycling lead to the reduction of the hull's overall impact. It should be noted that through the other solutions, the marine eutrophication indicator is the least compensated by recycling. 
Fig. 4 Fossil depletion, complete life cycle of the aluminum hull (scenario 1)-method ReCiPe Midpoint (H) v1.06

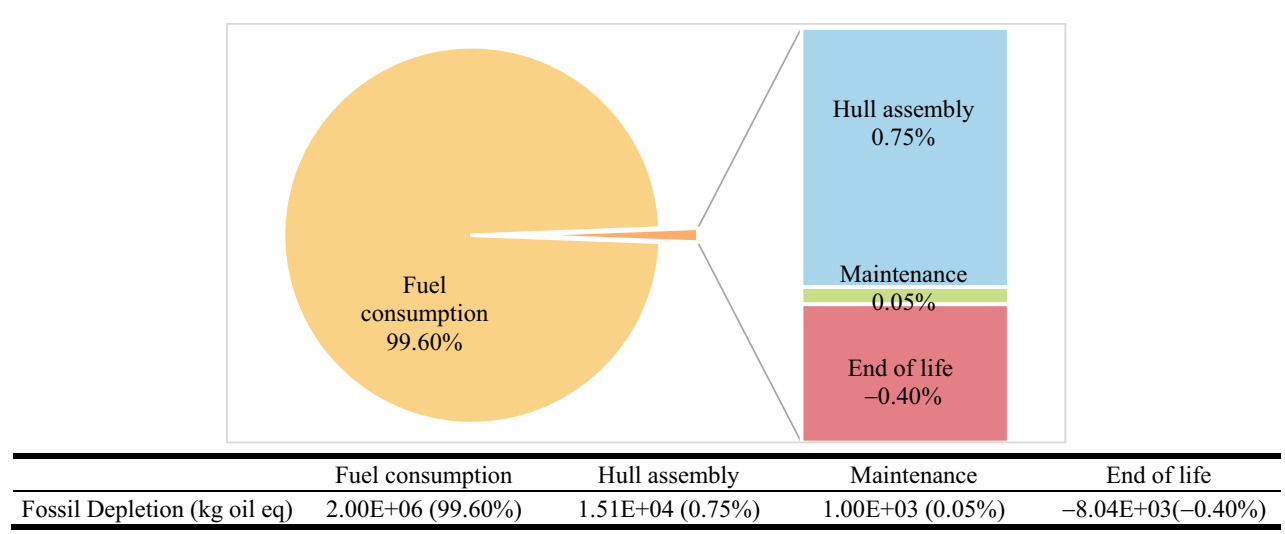

For the other materials, this gain is less marked seeing that the use of metals (stainless steel) is secondary with regard to the other raw materials used. Nevertheless, this gain cannot be overlooked once again. We must take into account that our recycling scenarios are fairly optimistic in the sense that it is difficult to separate many metals from the rest of the structure once the hull is assembled and has been used. Moreover, recycling can continue almost infinitely for metals like aluminum and steel.

\subsection{Global comparison of four scenarios}

Regarding Fig. 5, the most environmentally damaging scenario is no longer the aluminum construction. The distribution between the solutions (aluminum and composite) is therefore inverted, compared to Fig. 3, when we consider in Fig. 5 the whole life cycle of the boat. The composite solution becomes the most influent scenario, with three exceptions on our selection of indicators: the depletion of metal resources and ecotoxicity to the detriment of the aluminum solution, and the traditional wood solution causes the most change in natural lands.

That can be explained by several principal factors:

- Low recyclability at life's end for the composites solution, only the pieces with a low percentage of metal can be recycled. The valorization of the used for solid recovered fuel (SRF) is the most beneficial process at present

- The reduced life span of this scenario 2 compared to the three other solutions which in fact increases the reference flux and the impacts
Fig. 5 Comparison of the complete hull life cycle in the four scenarios excluding fuelMethod ReCiPe Midpoint $(\mathrm{H})$ v1.06

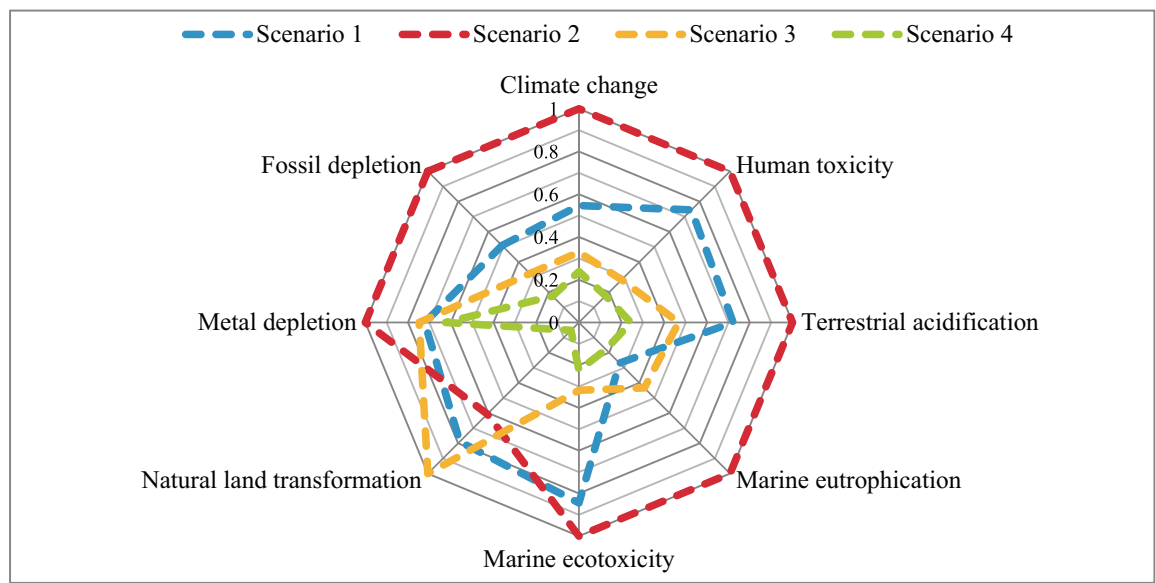

\begin{tabular}{lllrrr}
\hline Impact category & Unit & \multicolumn{1}{c}{ Scenario 1} & \multicolumn{1}{c}{ Scenario 2 } & \multicolumn{1}{c}{ Scenario 3 } & Scenario 4 \\
\hline Climate change & $\mathrm{kg} \mathrm{CO}$ eq & $4.19 \mathrm{E}+04(55 \%)$ & $7.67 \mathrm{E}+04(100 \%)$ & $2.52 \mathrm{E}+04(33 \%)$ & $1.82 \mathrm{E}+04(24 \%)$ \\
Human toxicity & $\mathrm{kg} \mathrm{1.4-DB} \mathrm{eq}$ & $2.08 \mathrm{E}+04(74 \%)$ & $2.80 \mathrm{E}+04(100 \%)$ & $7.90 \mathrm{E}+03(28 \%)$ & $4.93 \mathrm{E}+03(18 \%)$ \\
Terrestrial acidification & $\mathrm{kg} \mathrm{SO}_{2}$ eq & $1.73 \mathrm{E}+02(72 \%)$ & $2.40 \mathrm{E}+02(100 \%)$ & $1.12 \mathrm{E}+02(47 \%)$ & $5.83 \mathrm{E}+01(24 \%)$ \\
Marine eutrophication & $\mathrm{kg} \mathrm{N}$ eq & $1.01 \mathrm{E}+01(27 \%)$ & $3.73 \mathrm{E}+01(100 \%)$ & $1.62 \mathrm{E}+01(43 \%)$ & $6.66 \mathrm{E}+00(18 \%)$ \\
Marine ecotoxicity & $\mathrm{kg} \mathrm{1.4-DB} \mathrm{eq}$ & $4.77 \mathrm{E}+02(84 \%)$ & $5.65 \mathrm{E}+02(100 \%)$ & $1.79 \mathrm{E}+02(32 \%)$ & $1.26 \mathrm{E}+02(22 \%)$ \\
Natural land transformation & $\mathrm{m}^{2}$ & $8.40 \mathrm{E}+00(79 \%)$ & $6.45 \mathrm{E}+00(61 \%)$ & $1.06 \mathrm{E}+01(100 \%)$ & $5.55 \mathrm{E}-01(5 \%)$ \\
Metal depletion & $\mathrm{kg} \mathrm{Fe} \mathrm{eq}$ & $4.60 \mathrm{E}+03(72 \%)$ & $6.38 \mathrm{E}+03(100 \%)$ & $4.77 \mathrm{E}+03(75 \%)$ & $3.98 \mathrm{E}+03(62 \%)$ \\
Fossil depletion & $\mathrm{kg} \mathrm{oil} \mathrm{eq}$ & $1.23 \mathrm{E}+04(51 \%)$ & $2.42 \mathrm{E}+04(100 \%)$ & $7.84 \mathrm{E}+03(32 \%)$ & $4.22 \mathrm{E}+03(17 \%)$ \\
\hline
\end{tabular}


- The heavy use of harmful compounds for human life and the environment to manufacture and maintain composites hull

The second remark is that wooden boat hull remains the least environmentally damaging and retains a good margin with the aluminum solution, excepting marine eutrophication and natural land transformation that are largest for scenario 3 . Concerning metal depletion, wooden scenarios and aluminum are very close. The interest of the aluminum can be found here, when it can be recycled to rebuild another product.

Between wooden boat hulls, scenario 4 remains the last environmentally damaging compared with exotic wood and retain a large interest concerning "natural land transformation." Maritime pine is a local species but comes from cultivated trees. Harvesting generates an acceleration of carbon capture and storage when exotic wood harvesting is considered to distort ecosystem.

The benefits of using maritime pine have been shown on all the sets of indicators with a very substantial gain to be made between the composite solution and the Greenboat. Moreover, we have noted that the aluminum solution, which is often cited as the example of the most environmentally respectful solution, is in fact ranked below the maritime pine hull.

Our life cycle assessment seems to demonstrate that maritime pine used instead of imported woods seems better from both economic and environmental points of view.

\section{Conclusions}

During data collection and after the impact study, we identified three priority issues for the optimization of boat building and in particular for the construction of wooden boats at the Dubourdieu 1800 boatyard. These three lines are the following:

- A consideration of the materials used

- An improvement of the boats' efficiency

- An optimization of wooden boat building

The approach known as $3 \mathrm{RV}$ (reduce, reuse, recycle) should be at the forefront in the design of the boat. It is about designing boats whose architectures require fewer materials especially those from non-renewable metal and fossil resources. Re-using elements from an old boat should be preferred over an assembly using only new elements. It is also a question of anticipating the end of the life cycle and looking forward to dismantling procedures and to a high level of recyclability. Even so, a not insignificant amount can be valorized and so processes which are both apt and well adapted should be put in place.
These first results allowed validation for the choice of maritime pine as a reference material for the developments of economic, touristic, and environmental aspects.

Acknowledgments The authors extend their warmest thanks to the Cluster ABOVE who financed the research and in particular to the Dubourdieu 1800 boatyard (Mr Emmanuel Martin) who built the Greenboat and who supplied us with a great quantity of data for our LCA.

\section{References}

Bertram C, Rehdanz K (2013) On the environmental effectiveness of the EU Marine Strategy Framework Directive. Mar Policy 38:25-40

Bureau Veritas (2012) Stresses and safety coefficient. Part B, Ch 7, Sec 4, pp 159-160

Cabezas-Basurko O, Mesbahi E, Moloney SR (2008) Methodology for sustainability analysis of ships (review). Ships Offshore Struct J 3(1):1-11

Champion J-B, Houlou-Garcia A, Lesdos-Cauhapé C, Quénechdu V (2013) En 2012, $90 \%$ des déchets industriels triés sont valorisés. INSEE National Institute of statistics and economic studies, http://www.insee.fr/fr/themes/document.asp?ref_id=ip1535

COBAS (2010) Call for Greenboat program. http://www.agglo-cobas.fr/ images/upload/bateau_propre_appel_a_projet.pdf. South Arcachon Bassin Community

Curran MA (2012) Life cycle assessment handbook: a guide for environmentally sustainable products. ISBN: 978-1-118-09972-8. Wiley, $640 \mathrm{pp}$

D'Aboville G (2009) Boating and environment. Part 2. Environmental impact of boat life cycle. Ministry of ecology. CSNPSN Council of sport and recreational boating. $72 \mathrm{pp}$

EcoNav network (2011) Second life for boats. Internal report University Bretagne Sud

EcoNav network (2012) Environmental impact analysis of pleasure boat. Internal report University Bretagne Sud

European Commission (2010) ILCD handbook: general guide on LCAdetailed guidance, Jt Res. 417. doi: 10.2788/38479

Foundation APER (2012a) Datas of boat deconstruction. Internal report. APER Environmental association for the boating sector

Foundation APER (2012b) Maps of authorised deconstruction society 48 sites in France. Internal report. APER Environmental association for the boating sector

Goedkoop MJ, Heijungs R, Huijbregts M, De Schryver A. Struijs J, Van Zelm R (2009) ReCiPe 2008, A life cycle impact assessment method which comprises harmonised category indicators at the midpoint and the endpoint level; First edition Report I: Characterisation; 6 January 2009, http://www.lcia-recipe.net

Grimaud G, Pommier R, Perry N (2013) Rapport LCA of different material to made boat hull. Internal report Project ABOVE+2. University of Bordeaux

INSEE (2009) E11 shipbuilding industry in France. National Institute of statistics and economic studies.

IPCC (2014) Climate change 2014: impacts, adaptation, and vulnerability Chapter 8: transport. Work Gr III. Inter governmental panel on climate change Berlin, p 117

ISO (2006) ISO 14040: life cycle assessment—principles and framework. Environ Manag 3:28. doi:10.1002/jtr

Jacob A (2012) Composite boat building trends. Reinf Plast 56:3

Lavalette A, Pommier R, Danis M, Castéra P (2012) Tension-shear (TS) failure criterion for wood composite designed for shipbuilding applications. World Conf Timber Eng Sessin 11:8 
Levrel H, Jacob C, Bailly D et al (2014) The maintenance costs of marine natural capital: a case study from the initial assessment of the Marine Strategy Framework Directive in France. Mar Policy 49:37-47

Maritime International Organisation (2005) MARPOL 73/78 Annex VI : regulations for the prevention of air pollution from ships. Internal report Maritime International Organisation

Marsh G (2006) 50 years of reinforced plastic boats. Reinf Plast 50:16-19

Mcleod E (2013) Marine protected areas: static boundaries in a changing world. Encycl Biodivers 94-104

Ministry of Ecology (2012) Environmental code-Natura 2000 places. Ministry of Ecology

Ministry of Ecology (2013) Pleasur boat marquet. Department of infrastructure and transport and sea

Ministry of Housing Spacial Planning and the Environment (2009) ReCiPe 2008 (first edition) - report I: characterisation. Ministry of Ecology

Pensec LLE, Pinon H (2007) Age and life duration of boats. http://www. dirm-memn.developpement-durable.gouv.fr/IMG/pdf/fiche8 AML-2.pdf. Ministry of ecology

Pommier R, Elbez G (2006) Finger-jointing green softwood: evaluation of the interaction between polyurethane adhesive and wood. Wood Mater Sci Eng 1:127-137

Princaud M (2011) Development of an environmental decision support tool based on life cycle analysis integrated into a design process. $\mathrm{PhD}$. Arts et Métiers ParisTech
Princaud M, Cornier A, Froelich D (2010) Developing a tool for environmental impact assessment and eco-design for ships. HYPERLINK "http://www.researchgate.net/journal/1475-0902 Proceedings_of_the_Institution_of_Mechanical_Engineers_Part M Journal_of Engineering for the Maritime Environment". Proceedings of the Institution of Mechanical Engineers Part M. J Eng Marit Environ 224 (3):207-224

Ridley IG, Hutchinson KW (2012) The efficacy and acceptance of environmental impact and life cycle models within the design sector of the marine industry. International Conference on the Environmentally Friendly Ship; London; United Kingdom; 28-29 February 2012; pp 45-55. Code 91686

Roussel F (2012) Dossier : L'aluminium recyclé, un taux d'incorporation qui stagne à $30 \%$. Actu-environnement.com 10:3

Stoyell JL, Norman P, Howarth CR, Vaughan R (1999) Results of a questionnaire investigation on the management of environmental issues during conceptual design. A case study of two large madeto-order companies. J Clean Prod 7(6):457-464

Tukker DA (2002) Handbook on life cycle assessment: operational guide to the ISO standards. Volume 7. TNO Institute of Strategy, Technology and Policy

Van der Zee SC, Dijkema MB, van der Laan J, Hoek G (2012) The impact of inland ships and recreational boats on measured NOx and ultrafine particle concentrations along the waterways. Atmos Environ 55: 368-376 